\title{
Developing Moral Values in Primary School Pupils in Kenya
}

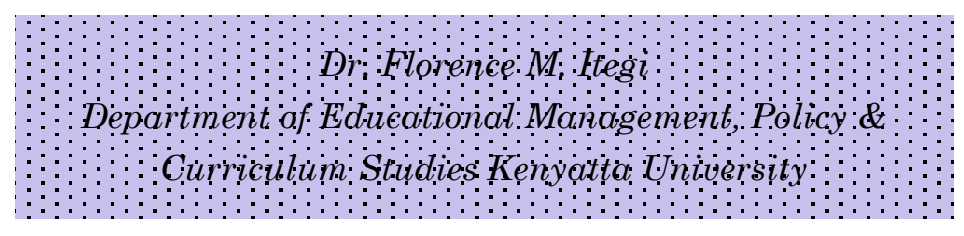

\section{Abstract}

Moral development is a complex effort to create an environment that enhances an individual's movement through stages of moral reasoning. This occurs in the context of interplay of factors like attitudes, beliefs and other external factors, such as peer, parental, and media influences. Furthermore, children acquire a wide range of behaviours, thoughts and feelings through observing others' behaviour (Bandura, 1997). Kenya like many other countries of the world has experienced rapid technological, economic and social changes which have overwhelming effects on both the individual behaviour and the society. Despite this awareness the pursuit of academic knowledge in primary schools continue to be viewed as more important and distinct from the acquisition and application of moral values. This paper examines the factors influencing moral development among pupils and scrutinizes impediments within and outside the schools that impact negatively on learners' behaviour in public primary schools in. The study used ex post facto design adopting both qualitative and quantitative approaches. 
Both multi-stage and random sampling techniques were used to select 100 pupils and 30 teachers. A questionnaire, an interview schedule an observation protocol to gather data on the general school environment were used Quantitative data were analysed and presented in percentages, frequency tables, and graphs and qualitative data were grouped into themes or categories, establishing connections and comparing them. The study found that parenting, urbanization, school environment, pupil characteristics impacted negatively on moral development among pupils. Consequently, pupils exhibited problem behaviours such as sexual relations, abusive language, gossiping, disobedience, indiscipline, disrespect, rudeness, dishonesty, conflicts, and bad groups as indicators of low moral status. The study recommends more learners' centred methods such as guidance and counselling, seminars, modelling, proper parenting, collaboration, pastoral care, strict rules, and teaching of moral values to be intensified to improve moral development among pupils.

\section{Introduction}

In essence, education should transform people and manifest its immediate effects on society and pass on knowledge, values and skills to the next generation to ensure continuity in transformation both at individual and societal levels. It impacts the society with human values and behav- 
iours and help individuals live lives of integrity geared towards innovation. Education becomes the hope and best way to achieve development with the people at the centre (Ntamushobora, 2007). Approaches of teaching moral values should be geared towards the affective domain-changing lives and developing wholesome character in the student which cannot be handled only at the cognitive domain. It was the main objective of this study to elicit information on possible approaches to improve moral development among pupils.

The Kenyan education system has undergone various reforms some in the areas which could be regarded as pertinent to values education. As the formal schooling constitutes the common vehicle for the development and reinforcement of basic social, moral, political and economic values, it is pertinent that internalization of values begins at the schooling and teacher education levels. Although formal religion is in the syllabus as part of the curricular, it is not always reflected in the attitudes expressed by the learners in and out of school (Brezinka, 1994).

Young people are capable of supporting themselves and the society if they are empowered 
to use their individual and collective creative resources. The education a society offers its adolescents reflects the sum total of what is held dear in that society. It socializes them and equips them with academic and social skills to enable them function positively in the society. This is one of the reasons why countries all over the world, including Kenya, spend large amounts of time, effort and money on education (Wambui, 1996). Despite the heavy investment by the government in the education sector, young people in and out of school continue to exhibit immoral behaviour which hurts the society in which their academic skills are highly needed. Worse still, some of the youth acquire high level of academic skills, but fail to enjoy the fruits of their education as they engage in self-destructive behaviour terminating their lives immaturely or end up living worthless lives. Thus, there is need to investigate the status of moral development among the youth.

A learner centred approach involves discussing with the learners about issues affecting them and together identifying constraints they commonly face in realizing their full potential and finding ways of strengthening their capacities to overcome such difficulties which often cause their exclusion 
and suffering. It is imperative that adults in the society including teachers and parents move the children from the known to unknown both in the academic matters as well as in their day-to-day concerns of their growth and development. Piaget and Kohlberg's theory of moral development supports step by step growth changing from one of unilateral respect to one of mutual respect. They advocate for a teacher-pupil relationship and subject matter that promotes maturity of outlook and autonomy in which young people can take responsibility for their own lives even long after the learning process. Moral reasoning enlightens learners on the existence and proper application of values in various contexts and using real examples yield better results (Wilson, 1990). However, the modern education in Kenya is often associated with the acquisition of academic skills and moral reasoning is of secondary concern. This study sought to find out moral development tenets in pupils.

Social, economic and cultural changes have been blamed for poor moral development. A study conducted in Nairobi and the surrounding areas (Shorter \& Onyancha, 1997) established that the traditional extended family which provided great material and moral support for young people, as 
well as a variety of role models in their preparation for adulthood is fast disappearing and that families are constantly evolving because of changes in economic and residential patterns. In households headed by single parents youth enjoy little or no supervision from their parents, who in most cases are busy either working or engaging in small scale income-generating activities (jua kali). Such youth were likely to engage in sexual activities than those whose parents supervise them strictly. Furthermore some parents were observed to engage in some questionable behaviours in the presence of their children, yet there is paucity of data in this field.

With appropriate policies put in place, young people would be able to face their developmental challenges and consequently contribute effectively to the processes and activities relating to development and governance of their respective society. Moral values provide the means with which to develop an understanding of one's characters, strengths and weaknesses, self respect and self discipline, clarifies the meaning and purpose of one's live and guides how one lives his/her life, make responsible use of their talents, rights and opportunities, in knowledge, wisdom, and understanding 
(Leicester, Modgil \& Modgil, 2000). After spending a significant portion of their life in school, a good number are still facing serious difficulties dealing with life challenges. Hence, there is every reason to believe that moral education is not getting adequate attention from the current education system.

Education sits on three stones: formal, informal and non-formal dimensions on which its beauty lies in and out of school endeavours and a lifelong process where knowledge for life and for a living is continuously imparted. However, over emphasis on formal education has reduced it to cognitive development which does not ensure the production of fully integrated, respectable and adaptable Kenyans for the $21^{\text {st }}$ century (Digolo, 2006). Just as academic skills are essential ingredients for development moral development is equally important to enable individuals take their destiny in their own hands so that they can contribute to their individual progress and that of the society. The challenge of this study is to find a balance between cognitive acquisition of academic knowledge and moral development of learners based on the premise that the outcomes of education can be effectively exercised and enjoyed only in a conducive moral environment. 
A large number of young people in and out of school seem to think more of what is to their personal material benefit than for others. Therefore, there is a growing concern about what kind of morality is being taught at the school because they seem unfamiliar with traditional virtues (Nguyen, 2005). The study focused on factors influencing moral development among pupils in public primary schools in Kiambu District, Kenya in the year 2009.

\section{Statement of the Problem}

The fruits of education can only be enjoyed in a just society. Fundamental human virtues are the heartbeat of a harmonious human society and moral integrity is indispensable if human society is to remain reasonably civilized (Sambuli, 2006). The past few years have seen immoral behaviour among pupils become an almost daily occurrence in and out of schools. Such includes alcohol and substance abuse, transactional sex, stealing, disobeying school rules, and use of vulgar language among others (Shorter \& Oyancha, 1997).

Furthermore, the Republic of Kenya (2001) established that moral decay was a major cause of unrest in school as evidenced by immoral practices exhibited by students in a culture of violence, mate- 
rialistic attitude, sexual relations with adults and peers, dishonesty and drug abuse among others that brought tension, conflict and suspicion among students and other members of the school community. Evidently, immoral behaviours have significantly contributed to increased dropout rates at a very early stage in education and such victims are perceived to be involved in worse forms of immoralities later in the society.

Teachers are teaching moral education for instance in form of Christian Religious Education (CRE) and Islamic Religious Education (IRE) where students perform well in examinations. In addition, guidance and counselling and even pastoral care programmes have been introduced to deal with immoral behaviour in schools. Yet, incidents of immoral behaviour have taken a worrying trend with numerous related problems in the education sector and in the wider society.

This prompted the researcher to establish the cause of the problem by studying factors influencing development of moral values among pupils. 


\section{Research Questions}

1. What is the moral status of primary school pupils in Kiambu district?

2. Besides teaching, what other roles do teachers play in developing moral values among pupils?

3. Apart from the school environment, what other factors influence moral development among pupils?

4. What approaches can be adopted to impact learners' behaviour in relation to moral development among pupils?

\section{Conceptual Framework}

Independent variables identified through literature such as family background, child characteristics, peer influence, mass media, the curriculum, school environment, and the community settings influence development of moral values among pupils. All these differ in the way they apply to different pupils, which in turn determine the way they react to behavior and emotional problems, which they encounter as shown in Figure 1. 
Figure 1: Conceptual Framework

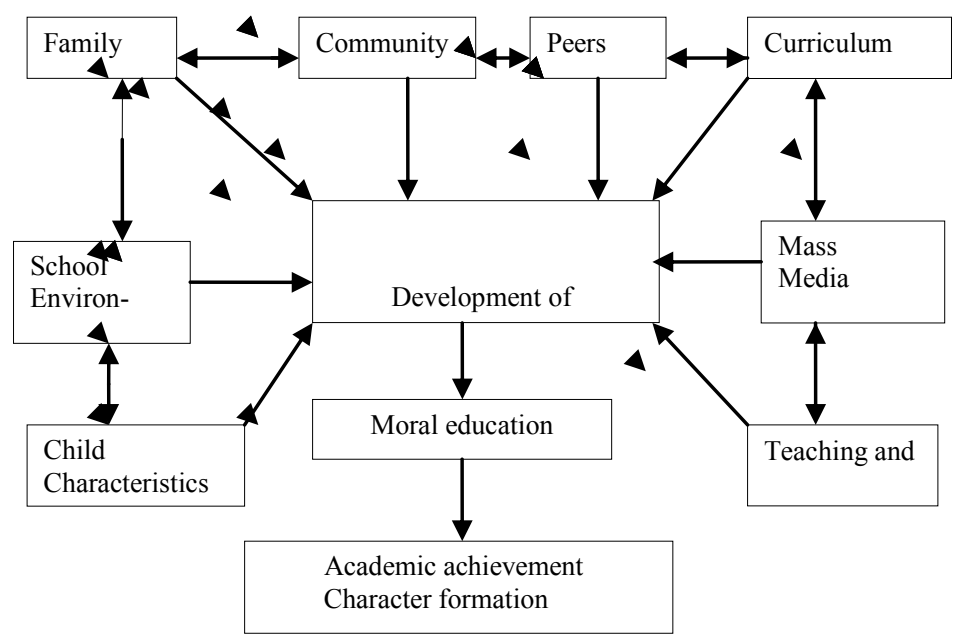

\section{Literature Review}

From the learning theories, it is evident that teaching of values must be based on developmental stages of children and appeal to all faculties of the children, and should involve more of doing than hearing, with constant reinforcement from the environment and especially the social group so as to impact behaviour.

Moral education faces a lot of challenges ranging from the philosophical basis of our education system, the curriculum orientation to academic achievement, collapse of traditions, modernization, 
and effects of urbanization among others. Shorter and Oyancha (1997) observed that urbanization had a stake in the prevailing moral crises among the youth. The video phenomenon in Nairobi applies the principle of economic rationalism where children are welcomed into video shows as customers to keep the business going. This situation illustrates a link between materialism, the media and the spread of immoralities as presented in the worsening moral image of school going children. in addition young children access the internet through mobile telephones and cyber cafes where they view phonographic materials. Without proper guidance, these children are more likely to practice what they view.

Absent parent hood and the consequent failure to provide instructions, models and sharing emotional concerns leads to behaviour problems in and out of schools. A case study involving 3,000 pupils in African and Asian schools established that parents do not have time to listen to their children. Working parents operate from work to clubs and straight to bed. So, their children see very little of them and end up in messes such as pregnancies, drug abuse and bad habits. The young people felt they needed parental love. The study further estab- 
lished that in such environment over two thirds of adolescents aged 15-19 years male and female have had sexual intercourse. Also adolescents and young adults (20-24 years) accounts for disproportionate share of the increase in reported cases of sexually transmitted diseases and at least one fifth of all people with AIDS are in their twenties and most are likely to become infected with HIV as adolescents (Barnet \& Francis, 1995).

When parents seemingly become out of reach to help children respond to the dynamics of life, young people have found warmth among peers who provide an environment in which individuals are able to test their abilities with freedom because they share similar challenges. This shift may result in rebellion leading to soaring relationships with adults (Mugambi \& Nasimiyu, 1999).

The school environment in terms of the physical environment, style of leadership and the curriculum is also a key player in developing moral values among pupils. All stake holders should play their respective roles more so to ensure learners are involved in shaping their own character through appropriate stimuli regularity review of the pedagogical methods of instruction and evaluation, cur- 
riculum materials and forms of school organisation (Ndirangu, 2004). He further contends that children learn more from the behaviour and attitudes of those around than the formal instruction or the manifest of the curriculum. To promote personal moral and social education, there is need to revise the examination system to increase the variety of testing procedures and widen the range of aptitudes measured.

Due to the interactive nature the mass media provides opportunities for children to learn especially due to its ability to engage more senses. However, the growing concern for the filthy shows and literature in homes, schools and along the streets by media producers cannot be underscored. Furthermore, computer/video games and television are a "school of violence", which teaches young people that crime is not reprehensive, but a good adventure (Kenya Institute of Education \& Life Skill Promoters, 2003).

Similarly, some advertisements in the media lure some youth into experimenting with them especially when it appeals to their ego and some sense of heroism. This may lead them into pornography, drugs and violence associated with poor aca- 
demic grades and poor socialization (Republic of Kenya Ministry of Education Science and Technology, 2001).

\section{Findings}

The study established that the status of moral development among primary school pupils was wanting. The schools encountered variety of problem behaviours. Figure 1 highlights the common problems as reported by teachers and pupils.

Figure 1: Common Problems Reported by Teachers and Pupils

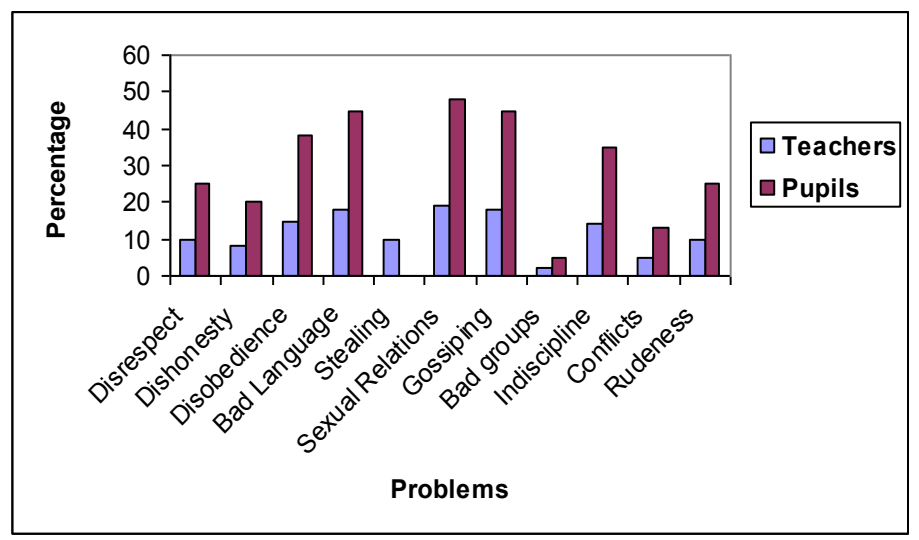

Most of the problems were attributed to urbanisation which initiated social-economic and cultural changes creating a generation of young adults and 
children at a cross-road. Majority of pupils had scattered ideas about their African culture, religion or language which they dismissed as old fashioned and they were not fully conversant with the modern practices which many endeavour to embrace as a sign of development. Majority of the students perceived the African cultural practices as evil or only worthwhile to the older generation. Evidently, very few learners could communicate in their mother tongue and those who used their mother tongue regularly were looked down upon as undeveloped. Teachers felt that majority of their learners perceived the adults as their enemies and effort to correct them brewed contempt. In many cases, the learners lacked guidance and the parents only learnt about their misbehaviour when too late to correct. In the words of Musamas (2006) we need to ask ourselves where are they coming from instead of where are they heading to? Have they had a companion from the early age or do we only raise concern when they mess.

It emerged that unfavourable school environment makes moral education difficult to transmit because most classes were overcrowded, with high teacher-pupil ratio, and a significant number of teachers are untrained, coupled with the numer- 
ous developmental problems of pupils ranging from lack of self awareness, mounting peer pressure, inability to handle relationships with their peers as well as their family members and the wider community, and the bombarding influence of the media. The demand on the side of the teacher was reported to be enormous. Regrettably, it is the gap between the home and the school where many children get involved in most immoral behaviours as the parents assume the teachers will teach them everything while on the other side the teachers are under pressure to implement the academic elements of the curriculum assuming other stakeholders will also do their part.

Economic disparity played a major role in hampering moral development among pupils. For instance, schools in wealthy neighbourhoods had neat compounds with flower gardens and modern buildings; such schools had few cases of problem behaviours. On the other hand, schools in poor neighbourhoods had unkempt compounds, not to speak of a school fence which was associated with low self esteem among learners; this impacted negatively on the moral development of pupils and the teachers' integrity. Many pupils from well managed schools identified with such schools even in 
their later life than those from poorly managed schools.

The study established that pupils learnt about variety of values from various sources such as parents, the teachers as well as elders. However, these values are not reflected in the pupils' behaviour. In addition, pupils were exposed to moral instruction, through teaching of values such as respect, obedience, humility, self-control, discipline, love, kindness, justice, responsibility and abstinence from sex by parents, teachers, elders, peers, media and the clergy. However, enormous environmental pressure inhabits moral development among the pupils as some have already fallen to the trap and their lives are in a mess after dropping out of school a teacher lamented in an interview:

In the immediate environs many social evils are the order of the day. Children encounter men and women drunk, drugs, vulgar language and prostitution, and are exposed to pornographic materials. The situation is worse in schools near shopping centres. In some regions I have heard teachers complain because drugs are sold in kiosks neighbouring the school and teachers fear for the children while the community appear to feel it is okay. The adults nowadays have little or no concern of what the 
young people do; this makes them to develop a negative attitude to teachers who they feel are always on their back.

Such scenarios were evident in schools that were found near shopping centres or in poverty stricken areas where the local communities engaged in all forms of activities regardless of their moral implications as their livelihoods including sale of alcohol, drugs, video showing and even prostitution.

On the other hand materialistic attitude in the society contributed to behaviour problems among the pupils. One teacher reported that:

The spirit of materialism is taking toll on moral development among young and old alike. Many young people are not in a position to secure gainful employment and therefore have joined gangs operating around shopping centres selling and taking drugs, alcohol and engaging in other types of crimes and they exert great influence on school going youth. There were many sources of values received by pupils including teachers, parents, elders, peers, church and mass media. However the attention given to teaching and learning in schools so as to pass in the national examinations. ... Compared to moral values gives the impression that academic skills are more favoured, powerful and more prestigious educationally. 
Among the factors believed to influence pupils' moral values, pupils reported pupils' attitude $38 \%$, teachers $13 \%$, and personal characteristics of pupils $13 \%$, peer influence $5 \%$, society values $3 \%$, and parents $3 \%$. On other hand, the teachers reported peers $20 \%$, parents $20 \%$, teachers $35 \%$, media $20 \%$, societal values $20 \%$, personal characteristics of pupils $20 \%$, rules and regulations $10 \%$, and the church $4 \%$.

From interviews with teachers other factors emerged including lack of consensus on the types of values to be taught to children posed a constraint to moral education. There were divergent views among teachers and parents on the kinds of values needed by the pupils that led to tensions and suspicion between the teachers and parents creating confusion among pupils who were not sure who was right between teachers and their parents and impacted negatively on moral development among pupils. This is exacerbated by multiplicity of lifestyles, varied cultural beliefs and customs that seemed to pose a challenge to moral education in schools. Teachers expressed concern that some of the parents did not exhibit appropriate behaviour to their children. Some teachers reported that "some female parents come to school in clothes that 
were very tight or exposed parts of their body in the name of fashion".

Strong influence of organized gangs emerged and more disturbing were the 'bad groups' with which some of the pupils associated with for example "Rasta", "Mungiki", "touts", and a few subscribed to "church youth", these groups exerts a lot of influence on our youth. Some pupils wore symbols of these groups in form of chains and bangles, shirts and caps and gestures. This further influences their personality in very many ways including their language, the kind of literature they read, way of dressing, relationships with others, and in general their world view. Such pupils exhibited open defiance to teachers' and parents' instructions, advice and even issued threats to those interfering with their lives because those gangs are likely to revenge if their members are offended either at school or home. The teachers disclosed that a small number of boys in class 7 and 8 had been recruited to join outlawed group "Mungiki" and feared many more could be recruited as they had been promised wealth if they remained faithful and persuaded others to join.

With regard to the roles teachers plaid, teachers emerged as good role models as reported by pupils, while majority of teachers felt they were just average. 
However, teachers strongly felt that pupils lacked adequate role models. Although teachers acknowledged their role of moulding pupils and that pupils look up to them for guidance, and utilised many forums in effort to promote moral development among pupils however, they were still constrained by many factors. Some teachers failed to offer required models for pupils to emulate; "some teachers lack integrity and self esteem in the way they dress, and carry themselves. Some teachers appear in one outfit through the week, come to school drunk and at times make shameful scenes in the local area as pupils watch especially while drunk".

Moral values were integrated in other subjects but traditional teacher centred approaches were adopted the main reason being that schools and individual teachers' work was judged by performance in national examinations'. There was great emphasis on academic skills giving moral development a secondary concern. In many cases learners were given attention when they misbehaved but they were not provided with guidance on what was expected of them especially on issues out of the academic field. Parents did not take time to advice their children about their sexuality and how to handle relationships with their peers and other 
members of the society because they assumed it was the work of teachers. On the other hand the teachers concentrated on teaching and learning to cover the prescribed syllabus at various class levels ignoring the normal growth issues of pupils. It was astonishing to observe that majority of the girls were taught about menstruation by their peers and even the parents did not care whether they hand the necessary materials to face such experiences. Many girls felt ashamed and even absented from school to avoid embarrassment. As a result many pupils exhibited frustrations and the consequent problem behaviour because they felt the adults were pretenders and did not care. Essentially the children missed important lessons they were supposed to learn from the parent and adults in the society in order to face the dynamics of their lives.

There was a general feeling that education has been misinterpreted to mean schooling (formal) ignoring its' informal and non-formal dimensions. Most parents were busy engaging especially in small scale businesses to make ends meet with little time to spend with their children and majority of parents perceived teaching of moral values to be the work of teachers. 
Faced with such crisis learners' centred methods to strengthen moral education were suggested: Strengthening of guidance and counselling, seminars for pupils and teachers, involving the clergy, introducing a system of rewards, educating of teachers, encouraging creativity, and cultivating a positive attitude to work, inviting role models to inspire pupils, and discouraging transfer of pupils with problem behaviour.

\section{Conclusion}

Moral development is more linked to doing than theoretical teaching and children in a society are a mirror of the actors in that society. Most of the schools are faced with moral issues even with the transmission of moral values from the home, and the school. Our schools are units of the society. The voices of teachers and pupils reveal a situation of widespread moral decadence and the need to consider a holistic a approach to reform the Kenyan society in which the competition to accumulate wealth among the rich is the driving force while the survivor for the poor overshadows every other values including sacrificing the lives of their own children. However, children have capacity to learn, if members of the society take collective responsibility 
to shape the behaviour of our children they will be like stars growing brighter with time.

\section{Recommendations}

The success of moral education depends on the concerted efforts of all three institutions of the society entrusted with the duty of transmitting values through generations namely the family, society and the school. The study made recommendations as follows:

- Parents and adults in the society need to discuss moral issues and respective choices with children so as to understand their situations, expectations, and help them make decisions, so as to maintain discipline while allowing a significant degree of autonomy. Parents need to collaborate with teachers to enhance school discipline while providing moral guidance to their children while out of school.

- The Ministry of Education, school administrators and teachers should improve the moral atmosphere of the school and to make moral values explicit in the mission and vision of schools. Schools to facilitate fora where parents and teachers discuss openly issues about the school 
and pupils' moral development. Teachers should act as models of moral behaviour in their interaction with students and act as facilitators rather than lecturers of moral values.

- The teacher training curriculum should adequately equip potential teachers with necessary knowledge and skills as custodians of moral behaviour and models. Moral education should be given priority in primary schools and adoption of approaches that involve behaviour change rather than passing of exams. 


\section{References}

Barnet, K., \& Francis, V. (1995). The micro politics of educational leadership. New York: McGraw-Hill.

Brezinka, W. (1994). Belief, morals and education. Singapore: Astigate.

Digolo, O. (2006). Challenges of education in Kenya in the $21^{\text {st }}$ century. Journal of the school of Education, 1(I-xxvii), xv-xvii.

Kenya Institute of Education and Life Skills Promoters. (2003). Guidance and counseling teachers handbook. Nairobi: Kenya Institute of Education.

Leicester, M., Modgil, C., \& Modgil, S. (2000). Moral education and pluralism. New York: Falmer Press.

Ministry of Finance \& Planning. Kiambu district development plan (2002-2008). Nairobi: Government Printers.

Mugambi, J., \& Nasimiyu, A. (1999 Jan). Moral and ethical issues in African Christianity. Journal of Ethical and Moral Issues 1(2). Nairobi: Action Publishers.

Musamas, J. (2006). Morality and education. Journal of the school of Education Moi University 1 (I-xxvii), pp. xv-xvii. 
Nguyen, T. (2005). First lessons for human beings have been ignored. Tuo Tree Newspaper. p. 10.

Nitamushobora, F. (January 2007). Towards education for holistic development. A desperate need for Africa. Perspectives: An Academic Journal of Daystar University, 1(2).

Piaget, J. (1965. The moral judgment of the child. New York: Free Press.

Republic of Kenya. (1997). Master plan on education \& training 1997-2010. Nairobi: Government Printers.

Republic of Kenya Ministry of Education Science and Technology. (2001). Report of the task force on student discipline and unrest in secondary schools. Nairobi: Jomo Kenyatta Foundation.

Sambuli, R. (2000). The heartbeat of indigenous Africa. New York: Garland Inc.

Sanaa Art Promotions. (2005). Badilika Uishi. Nairobi.

Shorter, A., \& Onyancha, E. (1997). Secularism in Africa: A case study of Nairobi city. Nairobi: Paulines Publications Africa

Steinberg, L. (1991). Adolescence. New York: McGraw Hill. 
Sugarman, B. (1973). The school and moral development. London: CROOM Helm.

Wambui, E. (1996). Kikuyu story telling as a method of communicating moral values. Unpublished thesis. Kenyatta University, Nairobi. 